\title{
ГЕОИНФОРМАЦИОННОЕ ОБЕСПЕЧЕНИЕ БЕЗОПАСНОЙ ЭКСПЛУАТАЦИИ ТРУБОПРОВОДНОГО ТРАНСПОРТА
}

\author{
Долгополов Даниил Валентинович1, \\ daniil.dolgopolov@gmail.co
}

\author{
Мелкий Вячеслав Анатольевич², \\ vamelkiy@mail.ru
}
Верхотуров Алексей Александрович², ussr-91@mail.ru

\author{
1 АО «СпейсИнфо Геоматикс», \\ Россия, 127490, г. Москва, ул. Декабристов, 51. \\ 2 Институт морской геологии и геофизики ДВО РАН, \\ Россия, 693022, г. Южно-Сахалинск, ул. Науки, 1Б.
}

\begin{abstract}
Актуальность исследования определяется необходимостью минимизации потерь на всех этапах цикла переработки и транспортировки углеводородного сырья и снижения загрязнения окружающей среды при утечках на трубопроводах. Обеспечение безопасности функционирования трубопроводных систем требует выполнения оперативных оценок ситуаций на любом из природных и хозяйственных объектов в пределах участка трубопровода. Наиболее совершенными инструментами для решения аналитических задач являются технологии геоинформационного картографрирования. Общее назначение создаваемых картографических изображений - помощь в организации безопасного размещения промышленных объектов при строительстве и выполнении эколого-геодинамического мониторинга во время эксплуатации трубопроводов.
\end{abstract}

Цель: проанализировать возможности применения различной геопространственной инфоормации, способствующей безопасной эксплуатации трубопроводных систем, обрабатьваемой посредством геоинформационных технологий. Для достижения цели в работе изучен отечественный и международный опыт предотвращения и ликвидации разливов нефти, разработаны требования к ГИС-технологии, аккумулирующей инсформацию о природных и техногенных процессах.

Объекты. Состав инфоормации и модулей для моделирования обстановки в составе ГИС должны содержать программные средства для анализа состоянии составляющих объектов трубопроводной инфраструктуры: основных и резервных ниток, лупингов, ответвлений, отводов, площадочных и внутриплощадочных объектов, производственных зданий и сооружений, резервуаров, технологических трубопроводов и т. д., а также составления картографических материалов для обеспечения мероприятий по предупреждению и организации ликвидации аварийных ситуаций.

Методы: дешифрирование аэрокосмических изображений трубопроводных систем, анализ материалов космических съемок, данных беспилотных летательных аппаратов и воздушного лазерного сканирования, изучение возможностей технологий геоинформационного картографирования, компьютерное моделирование состояния природно-техногенных комплексов.

Результаты. Произведен анализ нормативных документов, определяющих состав информации, необходимой для формирования тематических слоёв ГИС о состоянии компонентов окружающей среды и динамики природных процессов вдоль трасс трубопроводных систем. Модули информационной системы концентрируют данные о нарушенности и загрязненности среды, позволяющие создать карты сценариев техногенного воздействия и сформулировать рекомендации по оценке состояния и снижению негативных последствий. Экологическая безопасность транспорта углеводородов обеспечивается посредством моделирования развития природных процессов, оказывающих негативное влияние на объекты трубопроводной системы. Так, при затоплении участков трубопроводов во время наводнений, а также при попадании нефрти и нефртепродуктов в водотоки необходимо использовать высокоточные цисровые модели рельефра. Предлагается включение в состав системы модулей, поддерживающих анализ данных наблюдений, способствующих принятию решений в зависимости от сценариев динамики процессов, сопровождающихся аварийными разливами нефрти.

Выводы. Значимость проведенных исследований заключается в разработанной методике решения ряда вопросов, способствующих принятию решений по минимизации риска вероятных аварий при эксплуатации трубопроводных систем. Практическая значимость предлагаемой технологии сбора и обработки первичной инфрормации для наполнения баз данных геоинформационных систем заключается в том, что она позволяет получать сведения, достаточные для принятия решений при подготовке планов профилактических мероприятий и ликвидации аварийных разливов несттепродуктов и организации аварийно-восстановительных работ.

\section{Ключевые слова:}

Геопространственные данные, дешифрирование аэрокосмических изображений, геоинфоормационные технологии, трубопроводные системы, транспорт углеводородов, цифрровая модель рельефра, аварийные разливы нефтти и нефртепродуктов, ASTER, DEM, SRTM.

\section{Введение}

Развитие регионов всецело зависит от их природно-ресурсного потенциала. В любом регионе существует система эколого-географических ограничений, влияющих на режим природопользования и предопределяющих объемы необходимой информационной обеспеченности безопасной эксплуатации природно-техногенных комплексов. Среди основных 
направлений решения экологических проблем, связанных с развитием транспортных трубопроводных систем, значимую позицию занимает организация мониторинга и моделирования возможных последствий воздействия на окружающую среду [1].

Трубопроводные транспортные системы, проходя через природные территории (рис. 1), образуют сложные техногенные комплексы [2, 3]. Местоположение таких природно-территориальных формирований определяется рядом признаков, которые проявляются в разнообразии ландшафтных формаций, связанных с определенным воздействием объектов трубопроводов и их инфраструктуры.

Некоторые события (ЧС, изменение природной среды), связанные с эксплуатацией трубопроводных систем, оказывают существенное влияние на природ- ную среду и могут повлечь за собой огромные материальные потери и существенные экологические последствия. В то же время природные условия в районах прохождения трубопроводных систем оказывают влияние на состояние объектов трубопроводного транспорта.

Необходимость оперативной обработки и обеспечения обновленными данными определяет потребность в создании единой пространственной среды (геопространства) [4], ориентированной на задачи разных направлений и подразделений компаний, позволяющей анализировать данные эксплуатационных служб, геотехнического и экологического мониторинга, материалы полевых наблюдений и данные дистанционного зондирования Земли, а также обеспечивающей безопасную эксплуатацию трубопроводных систем [5].

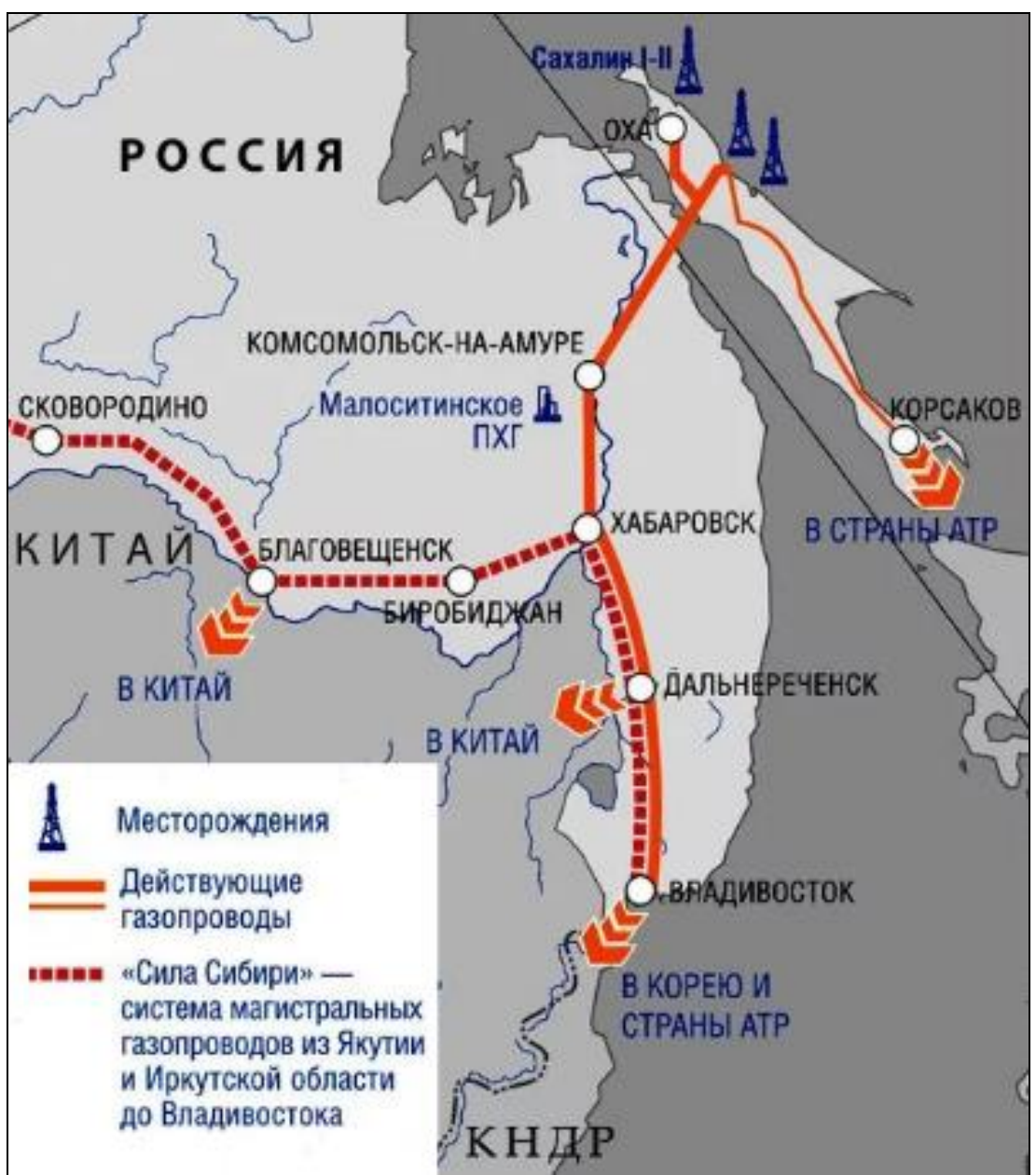

Рис. 1. Схема расположения основных трубопроводных систем Дальнего Востока [6]

Fig. 1. Layout of the main pipeline systems of the Far East [6]

\section{Общие требования к пространственным данным геоинформационных систем трубопроводного транспорта}

Методологической базой при разработке геоинформационных систем для трубопроводного транспорта могут служить теоретические и методические работы ученых в области геоинформатики и мониторинга природно-территориальных комплексов, в которых обоснованы возможности использования аэро- космических методов для создания тематических слоёв ГИС [7-16].

Быстрое изменение обстановки в районах прохождения трубопроводов требует проведения оперативного анализа ситуаций, которые складываются при возникновении неблагоприятных природных процессов. Геоинформационные системы, содержащие информацию, необходимую для формирования тематических слоёв о состоянии компонентов, динамике 
процессов, нарушенности и загрязненности природной среды позволяют создать карты сценариев техногенного воздействия и сформулировать рекомендации по снижению негативных последствий. Технологиче- ские схемы геоинформационного картографирования для оперативной оценки ситуации могут функционировать на основе реализации различных алгоритмов, однако суть их остается неизменной (рис. 2).

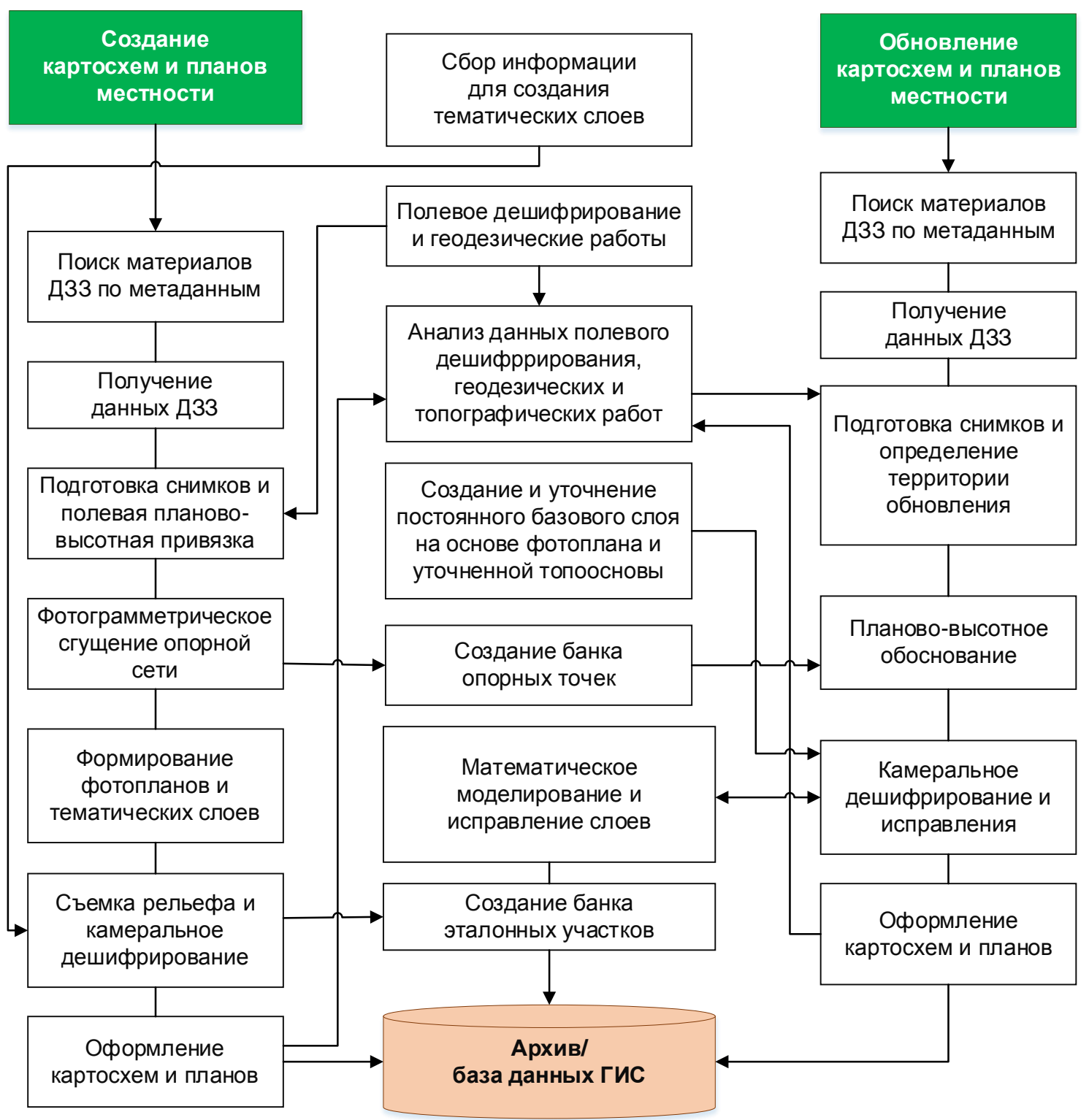

Рис. 2. Технология сбора и обработки первичной информации для наполнения геоинформационных систем трубопроводного транспорта

Fig. 2. Technology of collecting and processing primary information for filling geoinformation systems of pipeline transport

Формируя теопространство трубопроводного транспорта можно выделить общие требования к пространственным данным для всех направлений деятельности компаний, эксплуатирующих трубопроводные системы, определяемые в основном отраслевой спецификой, а также требования, связанные с производственной деятельностью по каждому направлению.

Общий состав пространственных данных может включать следующие группы данных:

- объекты линейной части трубопровода: основные нитки, резервные нитки, лупинги, ответвления, отводы и т. д.;
- структурное деление линейной части трубопровода (например, технологические участки);

- пересечения и сближения: подземные переходы через крупные водные преграды, малые водотоки, овраги и балки;

- границы и участки обслуживания/ответственности подразделений;

- площадочные объекты трубопроводного транспорта;

- внутриплощадочные сооружения: производственные здания, резервуары, технологические трубопроводы и т. д.;

- объекты, включенные в государственный кадастр недвижимости; 
- зоны, ограничивающие размещение трубопроводного транспорта: населенные пункты, особо охраняемые природные территории и т. д.;

- объекты реконструкции и нового строительства;

- сторонние объекты и т. д.

Производственные задачи, решаемые разными подразделениями, предъявляют дополнительные требования к пространственной локализации, составу и актуальности данных для каждого участка трубопровода, которые могут существенно различаться в зависимости от условий прохождения трассы.

Магистральный нефтепровод при любом виде прокладки должен иметь охранную зону, которая устанавливается нормативными документами:

- ограниченную полосой в 25 м с каждой стороны от осевой линии;

- на подводных переходах, расположенную между параллельными плоскостями, проведенными в 100 м от осей крайних ниток трубопроводов с обеих сторон.

В то же время для решения производственных задач на переходах магистральных нефтепроводов через водные преграды потребность в пространственных данных не ограничивается 100 метрами [17].

В соответствии с руководящими документами пространственные данные должны включать сведения о следующих объектах:
- участках магистральных нефтепроводов (нефтепродуктопроводов), пересекающих водные преграды (рис. 3);

- акваториях с максимально-возможной площадью загрязнения нефтью (нефтепродуктами);

- местах установки приспособлений для локализации распространения нефти (нефтепродуктов) в акватории водотоков.

\section{Геоинформационные системы} для безопасной эксплуатации трубопроводов

В рамках обеспечения экологической безопасности транспорта нефти и нефтепродуктов геоинформационное обеспечение позволяет решать следующие задачи:

- ведения тематических пространственных данных, необходимых для проведения инженерно-экологических изысканий;

- ведения реестров источников загрязнения воздуха и воды;

- расчета предельно допустимых выбросов;

- ведения реестра водозаборных скважин;

- ведения наблюдений за водными объектами;

- сопровождения работ по рекультивации земель;

- информационного обеспечения в условиях ЧС;

- моделирования разливов нефти.

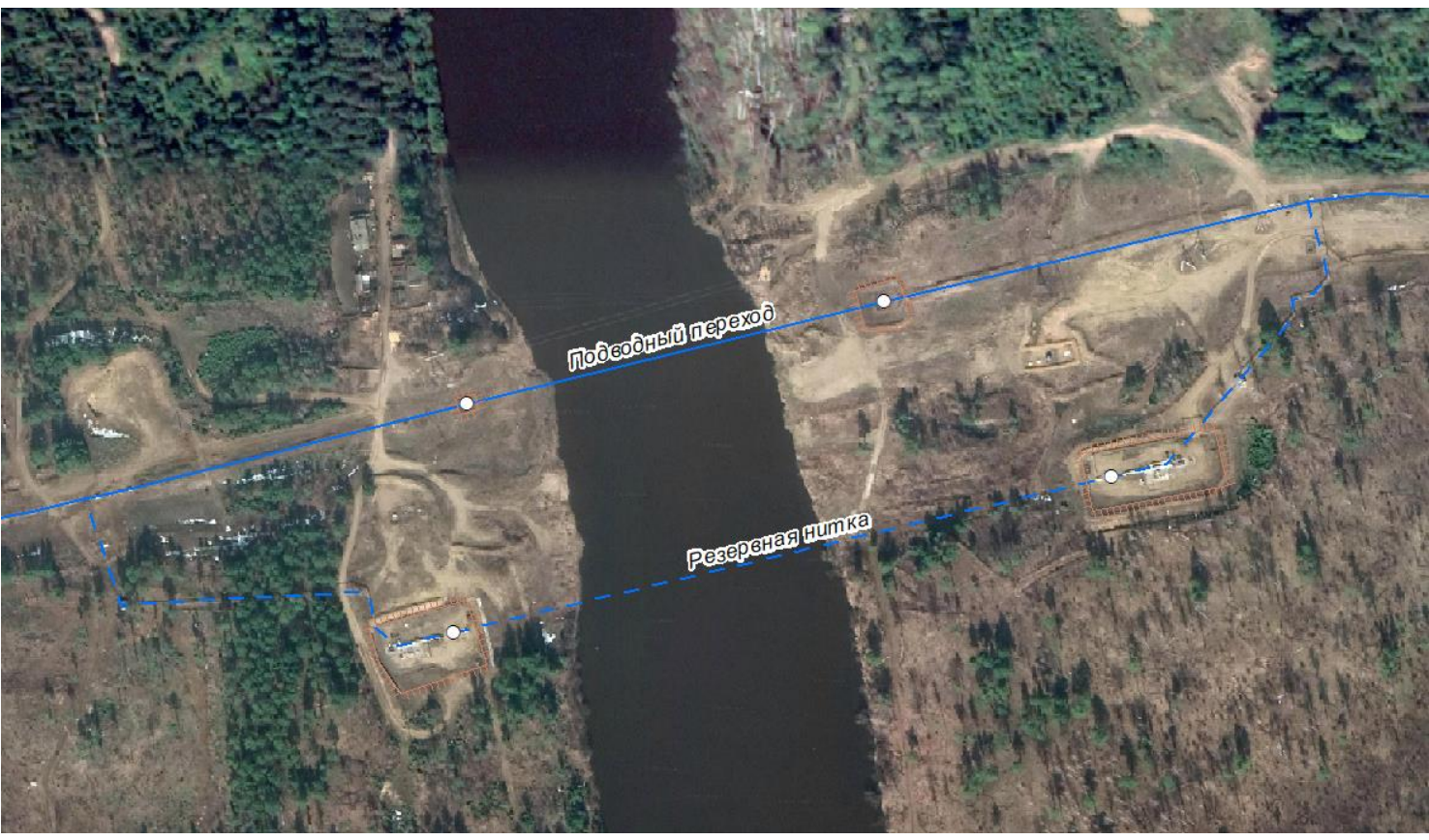

Pис. 3. Схема перехода магистрального нефтепровода через водную преграду

Fig. 3. Schematic map of the main oil-pipeline transition through water barrier

Геоинформационные технологии обеспечивают: сбор пространственных данных, их обработку, отображение в едином пространстве, интеграцию данных и знаний о территории для анализа, моделирования, прогнозирования, управления сохранением целостности окружающей среды [18-21].

Комплекс работ по формированию геоинформационного пространства включает: создание картографиче- ской основы, загрузку цифровых тематических карт и материалов дистанционного зондирования Земли, оптимизацию сети наблюдений с использованием ГИСанализа, проведение специальных съемок на местности, пробоотбора проб (почвы и воды), выполнение измерений, разработку и наполнение базы геоданных.

Функциональность геоинформационных систем для безопасной эксплуатации трубопроводного транспорта 
может включать прогнозные модули, обеспечивающие комплексный анализ данных наблюдений, а также ситуационные модули принятия решения, позволяющие строить сценарии развития ситуации с учетом текущей ситуации и информации об окружающей среде. Наполнение баз данных геоинформационных систем должно осуществляться в объеме, необходимом для работы функциональных приложений (модулей) и решения производственных задач (рис. 4).

Oсобое место в составе систем, обеспечивающих безопасную эксплуатацию трубопроводов, занимают модули моделирования и прогнозирования динамики развития негативных процессов и нарушений функционирования бесперебойной работы трубопроводного транспорта в результате стихийных природных явлений.
Серьезные последствия могут возникать в результате воздействия стихийных природных процессов: при затоплении объектов инфраструктуры трубопроводных систем во время наводнений, возникновении пожаров вдоль трасс трубопроводов, подтаивания вечномерзлых пород, повышении геодинамической активности территории, воздействии опасных морских явлений (нагонные и штормовые процессы, сложная ледовая обстановка) и т. д. Система мониторинга состояния объектов нефтегазового комплекса должна содержать модули для определения оценки риска Рассмотрим состав информации, необходимой для моделирования некоторых природных процессов с целью снижения риска.

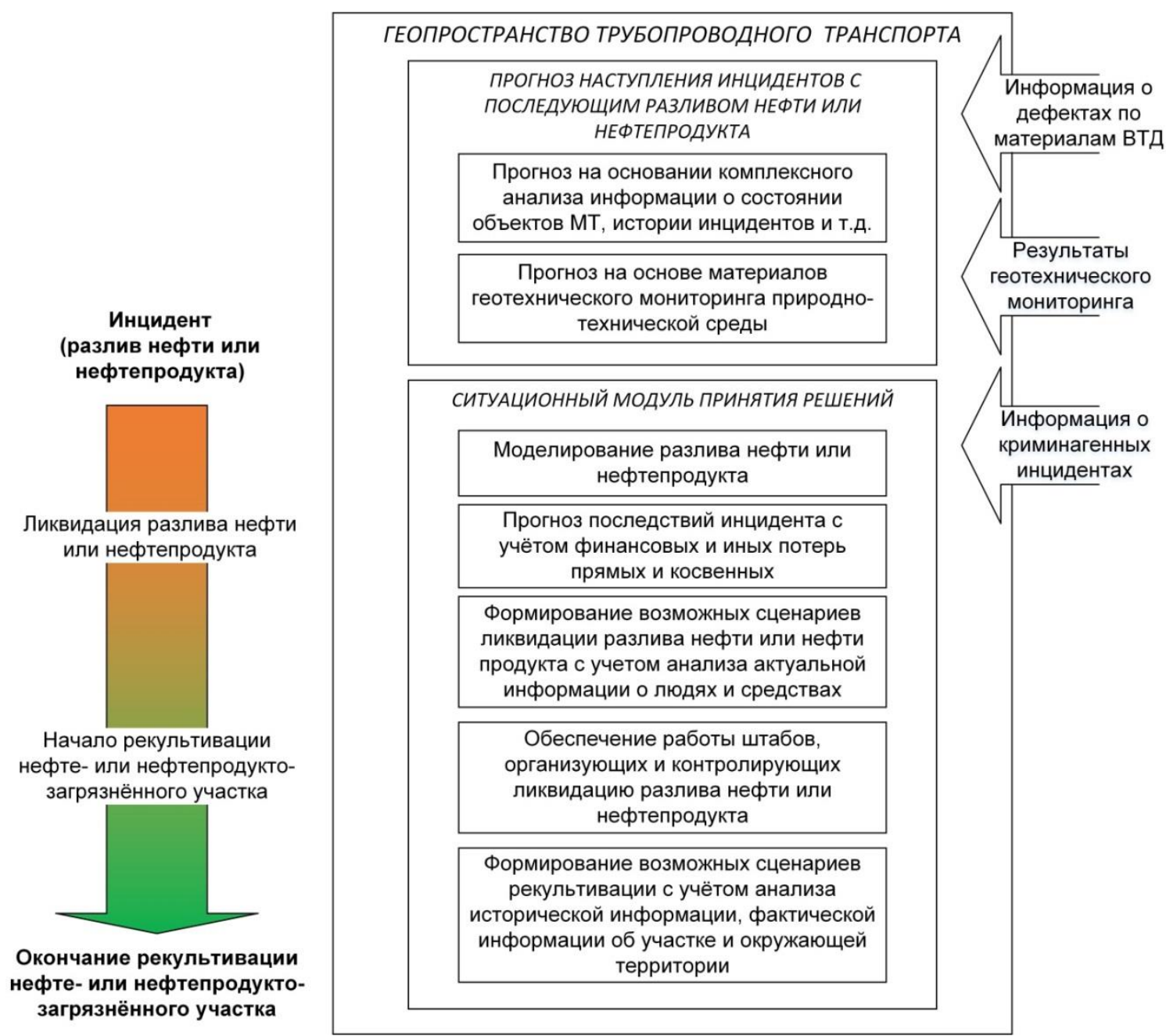

Pис. 4. Пример наполнения геоинформачионного пространства для обеспечения аварийно-восстановительных работ после разлива нефти или нефтепродуктов, прогноза последствий инцидента с учетом финансовых и иных потерь прямых и косвенных

Fig. 4. Example of filling the geoinformation space for emergency recovery operations after an oil or petroleum spill, forecasting the consequences of an accident taking into account financial and other losses, direct and indirect

Моделирование русловых процессов - довольно сложная задача, потому что поток жидкости подвергается многочисленным воздействиям, вызывающим разноплановые возмущения. Математические модели позволяют получать количественные характеристики трансформации движущихся вод- ных потоков [22-26]. Широкое распространение для решения гидрологических задач получили программные комплексы GRASS, SAGA, SWAT, в России - MIKE11 (Датского гидравлического института) и HEC-RAS (Центра инженерной гидрологии армии США) [27-29]. 
Система HEC-RAS состоит из четырех компонентов для анализа геометрии и состояния потока: 1) модуля расчета профиля поверхности воды с установившимся течением; 2) пакета моделирования нестационарного течения; 3) блока моделирования транспорта наносов; 4) модуля анализа качества воды. В дополнение к компонентам анализа система позволяет выполнять гидравлические расчеты после определения основных характеристик водного потока.

Геоинформационная система, предназначенная для обеспечения безопасной эксплуатации трубопроводов, должна аккумулировать картографические и гидрологические данные, необходимые для моделирования областей затопления [30]. Для моделирования необходимы сведения о строении речных долин, которые можно получить при исследовании цифровых моделей рельефа (ЦМР), с использованием информация гидрологических базах данных. Высокоточные ЦМР, созданные по материалам дистанционного зондирования, позволяют создавать корректные модели затоплений речных долин [31-34]. В базах ГИС также хранятся базовые картографические данные, материалы космических и аэросъемок, в том числе с использованием беспилотных летательных аппаратов (БПЛА) и средств воздушного лазерного сканирования (ВЛС), оцифровки топографических карт [35-38]. При гидрологических исследованиях активно используются глобальные модели рельефа (ASTER GDEM, SRTM) [39-45]. Глобальные ЦMP SRTM1 dEM и ASTER GdEM, созданные по материалам радиолокационной интерферометрии в С- и $\mathrm{X}$-диапазонах радиоволн с борта космических аппаратов «Индевор» и «Terra», обеспечивают моделирование затоплений [46-48].

Базы данных ГИС должны содержать разноплановую информацию. При строительстве и эксплуатации объектов, расположенных на вечномерзлых грунтах и в зонах повышенной сейсмической активности, требуется проведение деформационного мониторинга $[49,50]$, для обеспечения анализа лесопирологической обстановки накапливаются сведения о состоянии растительных сообществ, так как горимость лесов зависит от состава древостоев. Регулярный комплексный экологический мониторинг служит информационной базой для проектирования мероприятий по снижению негативных процессов [51-53].

\section{Планирование мероприятий по предупреждению и ликвидации аварийных разливов нефти и нефтепродуктов}

В соответствии с Законодательством Российской Федерации предприятия, эксплуатирующие опасные производственные объекты, должны обеспечить ликвидацию последствия аварий, иметь штатных специалистов и технические средства для восстановительных работ [54].

Планы по ликвидации аварийных разливов нефти разрабатываются и осуществляются в соответствии с российским законодательством, а также руководствами по предотвращению и ликвидации аварийных разливов нефти, разработанными нефтяными компаниями [55]. Планы предусматривают:
- активное внедрение превентивных мер;

- комплексное обучение специалистов по ликвидации разливов нефти (ЛРН);

- немедленное реагирование в случае потенциального разлива нефти силами заранее созданных подразделений по ЛРН, располагающих хорошо обученными кадрами и необходимым оборудованием.

Серьезную работу приходится проделывать компаниям при подготовке планов ЛРН для трубопроводов, которые пересекают крупные водные преграды, в особенности морские проливы в дальневосточном регионе, где порой складывается сложная ледовая обстановка (рис. 5). План ЛРН компании «Эксон Нефтегаз Лимитед» для проекта «Сахалин-1» раскрывает аспекты ликвидации разливов нефти, описанные в виде двух отдельных книг, применительно к конкретным условиям Сахалинской области и Хабаровского края. План содержит сведения о составе и объеме мероприятий по предупреждению и ликвидации чрезвычайных ситуаций, связанных с разливом нефти (ЧС(Н)), конкретизирует вопросы, рассмотренные в оперативных и территориальных планах.

План содержит конкретные сведения, касающиеся конкретных объектов, и справочные материалы. Ocновное внимание в Плане ЛРН уделяется вопросам организации практических действий, направленных на повышение эффективности мероприятий по реагированию и сведению к минимуму негативного воздействия на окружающую среду. Никакие экономические результаты производственной деятельности не важны настолько, чтобы ради них можно было пожертвовать безопасностью персонала и работ. Основная задача состоит в предотвращении аварий, $($ ЧС $(\mathrm{H}))$ и в обеспечении безопасности персонала.

Хочется отметить комплекс мер по предотвращению и уменьшению объёмов потенциальных разливов нефти, предусмотренный для эксплуатации трубопроводных систем консорциума «Сахалин-1»:

- трубопроводы запроектированы с прочностью на разрыв, достаточной для сохранения целостности при сейсмических событиях, с периодом повторяемости в 1000 лет для участков, проложенных на суше, и 2000 - в морских условиях;

- промысловые трубопроводы обеспечены системой автоматического отключения при утечках с задвижками через каждые 30 км на всем протяжении от Чайво до Де-Кастри;

- введена в эксплуатацию современная технология измерения толщины стенок и диагностики коррозии с контролем электрического потенциала;

- проводятся плановые инспекции трубопроводов.

\section{Заключение}

Модули геоинформационной системы, аккумулирующие данные о нарушенности и загрязненности среды, должны обеспечивать создание карт сценариев техногенного воздействия и способствовать выработке рекомендаций по оценке состояния и снижению негативных последствий. 

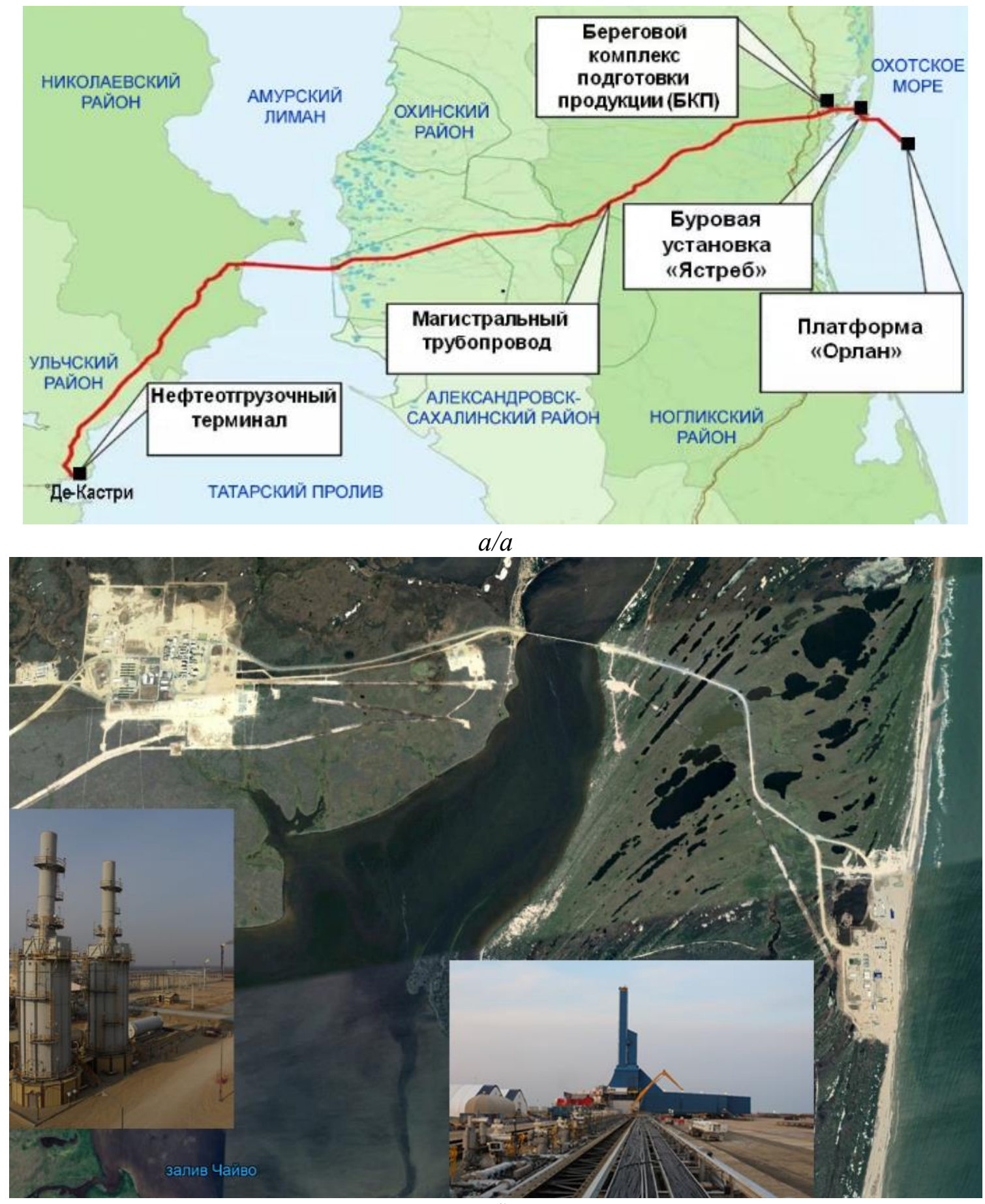

$\sigma / b$

Рис. 5. Общий план трубопроводных систем, работающих в рамках проекта «Сахалин-1» (а), производственная площадка буровой установки «Ястреб» и береговой комплекс подготовки продукции на космическом снимке Landsat-8 (Сайm GoogleEarth). Фото В.A. Мелкого (б)

Fig. 5. General plan of the pipeline systems operating under the Sakhalin-1 project (a), the production site of the Yastreb drilling rig and the onshore product preparation complex in the Landsat-8 satellite image (GoogleEarth website). Photo by V.A. Melkiy (b)

Для обеспечения мониторинга фактического положения объектов трубопроводного транспорта и состояния среды в местах их расположения целесообразно использовать данные дистанционного зондирования среднего и сверхвысокого разрешения $(<1$ м), материалы АФС, съемок БПЛА, высокоточных геодезических измерений, обеспечивающие необходимую точность и детализацию для корректного распознавания объектов.

Моделирование развития ситуаций при затоплении участков трубопроводов во время наводнений, а также при попадании нефти и нефтепродуктов в водотоки создается с использованием высокоточных цифровых моделей рельефа. 
В состав ГИС необходимо включить модули, поддерживающие анализ данных наблюдений и способствующие принятию решений в зависимости от сценариев динамики процессов, приводящих к аварийным ситуациям с утечками нефти.

\section{СПИСОК ЛИТЕРАТУРЫ}

1. Качур А. Н., Бакланов П. Я. Эколого-географические проблемы и ограничения в региональном развитии // Геосистемы Дальнего Востока России на рубеже XX-XXI веков в 3 т. Т. 3. Территориальные социально-экономические структуры / отв. ред. П.Я. Бакланов, М.Т. Романов. - Владивосток: Дальнаука, 2012. - С. 111-118

2. Дубровский А.В. Формирование техногенных природнотерриториальных комплексов нефтегазовых месторождений севера Сибири // Сборник научных трудов аспирантов и молодых ученых Сибирской государственной геодезической академии / под общ. ред. Т.А. Широковой. - Новосибирск СГГА, 2004. - С. 19-24.

3. Дубровский А.В. Базовые принципы геоинформационного обеспечения безопасной эксплуатации промышленных объектов // Всероссийская научная Интернет-конференция с международным участием: материалы конференции. - Казань, 5 июня 2014. - Казань: ИП Синяев Д.Н., 2014. - С. 14-17.

4. Карпик А.П. Концепция геоинформационного пространства // Материалы международной научно-технической конференции, посвященной 225-летию МИИГАиК. - М.: МИИГАиК, 2004. С. 434-438.

5. Долгополов Д.В. Использование данных дистанционного зондирования Земли при формировании геоинформационного пространства трубопроводного транспорта // Вестник Сибирского государственного университета геосистем и технологий (СГУГиТ). - 2020. - Т. 25. - № 3. - C. 151-159. DOI: 10.33764/2411-1759-2020-25-3-151-159

6. «Стройтрансгаз» обустроит инфраструктуру Чаяндинского нефтегазоконденсатного месторождения // Сайт ООО «Агентство Бизнес Новостей». URL: https://abnews.ru/tag/zaostrojtransgaz/ (дата обращения 25.01.2021).

7. Савиных В.П., Крапивин В.Ф., Потапов И.И. Информационные технологии в системах экологического мониторинга. - М. ООО «Геодезкартиздат», 2007. - 392 с.

8. Савиных В.П., Цветков В.Я. Геоданные как системный информационный ресурс // Вестник Российской академии наук. - 2014. - Т. 84. - № 9. - С. 826-829.

9. Зверев А.Т., Малинников В.А. Космический геоэкологический мониторинг северных территорий России // Известия высших учебных заведений. Геодезия и аэрофотосъемка. - 2011. № 6. - С. 68-73.

10. Бондур В.Г. Аэрокосмический мониторинг нефтегазоносных территорий и объектов нефтегазового комплекса. Реальности и перспективы // Аэрокосмический мониторинг объектов нефтегазового комплекса / под ред. академика В.Г. Бондура. М.: Научный мир, 2012. - С. 15-37.

11. Карпик А.П. Методологические и технологические основы геоинформационного обеспечения территорий: монография. Новосибирск: СГГА, 2004. - 260 с.

12. Методология геоэкологической стандартизации территории как основа геоэкологической безопасности / Д.А. Маркелов, А.В. Маркелов, Н.Я. Минеева, М.А. Григорьева, А.П. Акользин, Д.А. Шаповалов, А.О. Хуторова // Проблемы региональной экологии. - 2017. - № 3. - С. 16-25.

13. Лисицкий Д.В. Основные принципы цифрового картографирования местности. - М.: Недра, 1988. - 264 с.

14. Уставич Г.А., Утробина Е.С. Новый вид картографических произведений на районы субъектов Российской Федерации для широкого круга потребителей // Известия высших учебных заведений. Геодезия и аэрофотосъемка. - 2012. - № 2-1. C. $76-80$.

15. Пространственная оценка современных пожарных режимов лесных экосистем России / А.С. Плотникова, Д.В. Ершов, А.О. Харитонова, П.П. Шуляк, С.А. Барталев, Ф.В. Стыценко // Современные проблемы дистанционного зондирования Земли из космоса. - 2019. - Т. 16. - № 5. - С. 228-240.
Результаты проведённой работы могут быть внедрены и использованы при планировании мероприятий по профилактике и устранению аварийных разливов нефтепродуктов, обоснованных модельными сценариями.

16. Мелкий В.А. Теоретические основы и принципы построения единой системы мониторинга природной среды и техносферы // Известия высших учебных заведений. Геодезия и аэрофотосъемка. - 2002. - № 2. - С. 89-97.

17. РД-13.020.40-КТН-025-14 «Магистральный трубопроводный транспорт нефти и нефтепродуктов. Требования к разработке плана по предупреждению и ликвидации разливов нефти (нефтепродуктов) на переходах МН (МНПП) через водные преграды». - М.: ПАО «Транснефть», 2014. - 15 с.

18. Нефтяное загрязнение ландшафтов Чечни: распознавание на местности - «Технологии с одного взгляда» / Д.А. Маркелов, А.В. Маркелов, Н.Я. Минеева, А.П. Акользин, Б.И. Кочуров, Д.А. Шаповалов, А.О. Хуторова, М.А. Григорьева, Е.А. Чукмасова // Экология урбанизированных территорий. - 2018. № 2. - C. 52-60.

19. Castillo F. Managing Information Technology. - Luxembourg: Springer, 2016. $-246 \mathrm{p}$

20. Arun S.B., Kesavan K., Parivallal S. Recent advances in health monitoring and assessment of inservice oil and gas buried pipelines // Journal of the Institution of Engineers (India): Series A. 2018. - V. 99 - P. 729-740. DOI: 10.1007/s40030-018-0316-5

21. Геоэкологический анализ влияния трубопроводного транспорта на окружающую среду транзитных регионов / Л.А. Межова, А.М. Луговской, Ю.Н. Гладкий, А.Б. Глазьева, О.Ю. Сушкова, Л.Б. Вампилова, А.А. Соколова, Л.А. Луговская // Юг России: экология, развитие. - 2019. - Т. 14. - № 4. - С. 98-110.

22. Advances in the application of the SWAT model for water resources management / R. Jayakrishnan, R. Srinivasan, C. Santhi, J.G. Arnold // Hydrological Processes. - 2005. - V. 19(3). P. 749-762.

23. Global relationships between river width, slope, catchment area, meander wavelength, sinuosity, and discharge / R.P.d.M. Frasson, T.M. Pavelsky, M.A. Fonstad, M.T. Durand, G.H. Allen, G. Schumann, C. Lion, R.E. Beighley, X. Yang // Geophysical Research Letters. - 2019. - V. 46. - № 6. - P. 3252-3262.

24. Романовский Р.В. Применение методов компьютерного моделирования зон затопления при максимальных расчетных уровнях воды для решения проектных задач при рекультивации нарушенных земель, а также проектировании зданий и сооружений вблизи водных объектов // Известия Томского политехнического университета. Инжиниринг георесурсов. 2019. - T. 330. - № 2. - C. 186-201.

25. Dingman L. Physical hydrology. Third edition. - Long Grove, Illinois: Waveland press, Inc., 2015. - 643 c.

26. Yongzhi L., Wenting Z., Xinmin C. Flood emergency management using hydrodynamic modelling // Procedia Engineering. - 2012. - V. 28. P. 750-753. DOI: https://doi.org/ 10.1016/j.proeng.2012.01.802

27. Pay-per-hour water modelling // MIKE Powered by DHI. URL: https://www.mikepoweredbydhi.com/products/mike-on-saas (дата обращения 07.02.2021).

28. CESDb.com Civil Engineering Software Database. URL: https://www.cesdb.com/hydraulic-engineering/ (дата обращения 07.02.2021).

29. Пьянков С.В. Шихов А.Н.Геоинформационное обеспечение моделирования гидрологических процессов и явлений: монография. - Пермь, Пермский гос. нац. исслед. универ., 2017. $148 \mathrm{c}$.

30. Новаковский Б.А., Пермяков Р.В. Комплексное геоинформационно-фотограмметрическое моделирование рельефа. - М.: МИИГАиК, 2019. - 175 с.

31. Pike R.J., Evans I.S., Hengl T. Chapter 1. Geomorphometry: a breif guide // Geomorphometry: concepts, software, applications. Developments in soil science / Eds. T. Hengl, H.I. Reuter. - 2008. - V. 33. - P. 3-30. DOI: http://dx.doi.org/10.1016/S0166-2481(08)00001-9

32. Li Z.L., Zhu Q., Gold C. Digital terrain modeling. Principles and methodology. - Boca Raton: CRC Press, 2005. - 318 p. DOI: https://doi.org/10.1201/9780203357132 
33. Evaluation of recently released open global digital elevation models of Hubei, China / Z. Hu., J. Peng, Y. Hou, J. Shan // Remote Sensing. 2017. - V. 9 (3). - 262 p. DOI: https://doi.org/10.3390/rs9030262

34. Investigation on the use of geomorphic approaches for the delineation of flood prone areas / S. Manfreda, F. Nardi, C. Samela S. Grimaldi, A. C. Taramasso, G. Roth, A. Sole // Journal Hydrology. - 2014. - V. 517. - P. 863-876 DOI: https://doi.org/10.1016/j.jhydrol.2014.06.009

35. Технологические решения в области обеспечения геопространственной информации о магистральных трубопроводах и объектах их инфраструктуры / Е.И. Аврунев, Г.А. Уставич, А.О. Грекова, А.В. Никонов, В.А. Мелкий, Д.В. Долгополов // Известия Томского политехнического университета. Инжиниринг георесурсов. - 2020. - Т. 331. - № 7. - С. 188-201. DOI: https://doi.org/10.18799/24131830/2020/7/2729

36. Monitoring of gas pipelines - a civil UAV application D. Hausamman, W. Ziring, G. Schreier, P. Strobl // Aircraft Engineering and Aerospace Technology. - 2005. - V. 77. - № 5. P. 352-360. DOI: https://doi.org/10.1108/00022660510617077.

37. Kovačič B., Kamnik R. Accuracy of trigonometric heighting and monitoring the vertical displacements // Engineering modelling. 2007. - № 20. - P. 77-84. URL: https://www.researchgate.net/ publication/293730162_Accuracy_of_trigonometric_heighting_and_m onitoring_the_vertical_displacements (дата обращения 07.02.2021).

38. Хлебникова Т.А., Опритова О.А., Аубакирова С.М. Экспериментальные исследования точности построения фотограмметрической модели по материалам БПЛА // Интерэкспо ГеоСибирь. - 2018. - Т. 1. - № 4. - С. 32-37.

39. Implications of simulating global digital elevation models for flood inundation studies / L. Hawker, J. Rougier, J.C. Neal, P. Bates, L. Archer, D. Yamazaki // Water Resources Research. 2018. - V. 54. - Iss. 10. - P. 7910-7928. DOI https://doi.org/10.1029/2018WR023279

40. Niyazi B., Zaidi S.M.F, Masoud M.H.Z. Comparative study of different types of digital elevation models on the basis of drainage morphometric parameters (case study of Wadi Fatimah Basin, KSA) // Earth Systems and Environment. - 2019. - V. 3. - № 3. P. 539-550. DOI: https://doi.org/10.1007/s41748-019-00111-2

41. High-quality seamless DEM generation blending SRTM-1, ASTER GDEM v2 and ICESat/GLAS observations / L. Yue, H. Shen, L. Zhang, X. Zheng, F. Zhang, Q Yuan // Journal of Photogrammetry and Remote Sensing (ISPRS). - 2017. - V. 123. P. 20-34. DOI: https://doi.org/10.1016/j.isprspprs.2016.11.002

42. Santillan J R., Makinano-Santillan M., Makinano R.M. Vertical accuracy assessment of ALOS World 3D - 30 m Digital Elevation Model over northeastern Mindanao, Philippines // 2016 IEEE International Geoscience and Remote Sensing Symposium (IGARSS). - 2016. - P. 5374-5377. Available at https://ieeexplore.ieee.org/document/7730400 (дата обращения 07.02.2021).

43. Comparison of SRTM-V4.1 and ASTER-V2.1 for accurate topographic attributes and hydrologic indices extraction in flooded areas / A. Bannari, G. Kadhem, A. El-Battay, N. Hameid // Journal of Earth Science and Engineering. - 2018. - V. 8. - № 1. - P. 8-30. URL: $\quad$ https://pdfs.semanticscholar.org/958e/e8773691ac 91f61914277400872db025e7a1.pdf (дата обращения 07.02.2021)

44. Chen C., Yang S., Li Y. Accuracy assessment and correction of SRTM DEM using ICESat/GLAS data under data coregistration // Remote sensing. - 2020. - V. 12. - № 20. - P. 3435. DOI: https://doi.org/10.3390/rs12203435
45. Скрыпицына Т.Н., Флоринский И.В., Лущикова О.С. Сравнительная оценка точности квази-глобальных моделей рельефа AW3D30 DSM, ASTER GDEM и SRTM1 DEM // Известия высших учебных заведений. Геодезия и аэрофотосъемка. 2017. - № 5. - C. 86-90

46. On the vertical accuracy of the ALOS world 3D-30m digital elevation model / B. Caglar, K. Belek, C. Mekik, M. Ozendi // Remote Sensing Letters. - 2018. - V. 9 (6). - P. 607-615. DOI: https://doi.org/10.1080/2150704X.2018.1453174

47. Current status of Advanced Land Observing Satellite-3 (ALOS-3) / T. Imai, H. Katayama, H. Imai, Y. Hatooka, S. Suzuki, Y. Osawa // Proc. of SPIE, the International Society for Optical Engineering. France, Toulouse, Sept. 20-23, 2010. - V. 7826. - paper 7826-11. DOI: https://doi.org/10.1117/12.866289

48. Tarolli P., Mudd S. M. Introduction to remote sensing of geomorphology // Developments in Earth Surface Processes. 2020. - V. 23. - P. XIII-XV DOI: https://doi.org/10.1016/B978-0444-64177-9.09992-6

49. Технологические аспекты построения 3D-модели инженерных сооружений в городах арктического региона РФ / Е.И. Аврунев, А.В. Чернов, А.В. Дубровский, А.В. Комиссаров, Е.Ю. Пасечник // Известия Томского политехнического университета. - 2018. - Т. 329. - № 7. - С. 131-137.

50. Особенности выполнения деформационного мониторинга инженерных сооружений в условиях вечной мерзлоты / Г.А. Уставич, Е.И. Аврунев, В.Г. Сальников, В.К. Попов // Известия Томского политехнического университета. Инжиниринг георесурсов. - 2018. - Т. 329. - № 4. - С. 97-109.

51. Севастьянов Н.Н. Предложения по развитию корпоративной геоинформационной системы ПАО «Газпром» на базе использования аэрокосмической информации // Газовая промышленность. - 2018. - № 7 (771). - С. 18-25.

52. Экологический мониторинг и мероприятия по снижению уровня возможного негативного воздействия трубопроводов (Проект «Сахалин 2») на окружающую среду острова Сахалин / В.А. Мелкий, А.А. Верхотуров, Д.В. Долгополов, А.Н. Бурыкин, В.В. Ильин, А.А. Гальцев, О.М. Зарипов, Д.Г. Новиков, Я.П. Белянина, И.В. Еременко // Известия высших учебных заведений. Геодезия и аэрофотосъемка. - 2015. - № 4. - С. 101-108.

53. Liu W.T., Kogan F.N. Monitoring regional drought using the vegetation condition index // International Journal of Remote Sensing. - 1996. - V. 17. - № 14. - P. 2761-2782. DOI: https://doi.org/10.1080/01431169608949106

54. Постановление Правительства РФ от 31 декабря 2020 г. № 2451 «Об утверждении Правил организации мероприятий по предупреждению и ликвидации разливов нефти и нефтепродуктов на территории Российской Федерации, за исключением внутренних морских вод Российской Федерации и территориального моря Российской Федерации, а также о признании утратившими силу некоторых актов Правительства Российской Федерации // Информационно-правовой портал «Гарант.PУ». URL: http://www.garant.ru/products/ipo/prime/doc/ 400070332/ (дата обращения 07.02.2021).

55. Правила охраны магистральных трубопроводов. Нормативные документы по безопасности, надзорной и разрешительной деятельности в нефтяной и газовой промышленности. / Ответственные составители-разработчики: Ю.А. Дадонов, С.Н. Мокроусов. М.: Научно-технический центр по безопасности в промышленности Госгортехнадзора России, 2004. - Вып. 14. - 8 с.

Поступила 08.02.2021 2.

\section{Информация об авторах}

Долгополов Д.В., кандидат технических наук, ведущий научный сотрудник АО «СпейсИнфо Геоматикс».

Мелкий В.A., доктор технических наук, ведущий научный сотрудник лаборатории вулканологии и вулканоопасности Института морской геологии и геофизики ДВО РАН.

Bepхотуров A.A., кандидат технических наук, старший научный сотрудник Центра коллективного пользования, Институт морской геологии и геофизики ДВО РАН. 
UDC 528.88:502.36:004.94

\title{
GEOINFORMATION SUPPORT FOR SAFE OPERATION OF PIPELINE TRANSPORT
}

\author{
Daniil V. Dolgopolov'1, \\ daniil.dolgopolov@gmail.com \\ Vyacheslav A. Melkiy², \\ vamelkiy@mail.ru
}

\author{
Alexey A. Verkhoturov², \\ ussr-91@mail.ru \\ 1 SpacInfo Geomatics JSC, \\ 51, Dekabristov street, Moscow, 127490, Russia. \\ 2 Institute of Marine Geology and Geophysics of the Far East Branch of Russian Academy of Science (IMGG FEB RAS), \\ 1b, Nauki street, Yuzhno-Sakhalinsk, 693022, Russia.
}

The relevance of the research is determined by the need to minimize the losses at all stages of the cycle of processing and transportation of hydrocarbon raw materials and reduce environmental pollution from leaks in pipelines. Ensuring the safety of the functioning of pipeline systems requires performing operational assessments of situations at any of natural and economic objects within pipeline segment. The most advanced tools for solving analytical problems are technologies of geoinformation mapping. The general purpose of the created cartographic images is to help in organizing the safe placement of industrial facilities during construction and performing environmentalgeodynamic monitoring during pipeline operation.

The main aim was to analyze the possibilities of using various geospatial information that contributes to the safe operation of pipeline systems, processed through geoinformation technologies. To achieve this goal, the work examines the domestic and international experience in preventing and eliminating oil spills, and develops requirements for GIS technology that accumulates information about natural and man-made processes.

Objects. Composition of information and modules for simulation environment composed of GIS must contain the software for analysis of condition of the components of pipeline infrastructure: primary and backup threads, loopings, branches, bends, site and on-site facilities, industrial buildings, tanks, process piping, etc., and preparation of cartographic materials to ensure prevention and organization of emergency.

Methods: decoding of aerospace images of pipeline systems, analysis of space survey materials, data from unmanned aerial vehicles and aerial laser scanning, studying the possibilities of technologies of geoinformation mapping, computer modeling of the state of naturalanthropogenic complexes.

Results. The authors have analyzed the regulatory documents that determine the composition of the information necessary for formation of GIS thematic layers on the state of environmental components and the dynamics of natural processes along the routes of pipeline systems. The modules of the information system concentrate data on the disturbance and pollution of the environment, allowing you to create maps of man-made impact scenarios and formulate recommendations for assessing the state and reducing negative consequences. The work shown that the data of remote sensing of the Earth with different spatial resolutions, unmanned aerial vehicles and aerial laser scanning, accurate geodetic reference make it possible to form arrays of geospatial data required for modeling. The environmental safety of hydrocarbon transport is ensured by modeling the development of natural processes that have negative impact on the objects of the pipeline system. For example, when pipeline sections are flooded during floods, as well as when oil and petroleum products enter watercourses, it is necessary to use high-precision digital terrain models. It is proposed to include modules in system that support the analysis of observational data and facilitate decision-making depending on the scenarios of process dynamics, including in the case of emergency oil spills.

Conclusions. The significance of the work performed is to develop a methodology for solving a number of issues that contribute to decision-making to minimize the risk of possible accidents during the operation of pipeline systems. The practical value of the proposed technology for collecting and processing primary information for filling databases of geoinformation systems is that it allows you to obtain information sufficient for decision-making in preparation of plans for preventive measures and the elimination of emergency oil spills and the organization of emergency recovery operations.

\section{Key words:}

Geospatial data, decoding of aerospace images, geoinformation technologies, pipeline systems, transportation of hydrocarbons, digital terrain model, emergency oil and petroleum product spills, ASTER, DEM, SRTM.

\section{REFERENCES}

1. Kachur A.N., Baklanov P.Ya. Ekologo-geograficheskie problemy i ogranicheniya $\mathrm{v}$ regionalnom razvitii [Ecological-geographical problems and restrictions in regional development]. Geosistemy Dalnego Vostoka Rossii na rubezhe XX-XXI vekov v 3 t. T. 3 . Territorialnye sotsialno-ekonomicheskie struktury [Geosystems of the Russian Far East at turn of the XX-XXI centuries. In 3 vols. Vol. 3. Territorial socio-economic structures]. Eds. P.Ya. Baklanov, M.T. Romanov. Vladivostok, Dalnauka Publ., 2012. Vol. 3, pp. 111118.
2. Dubrovskiy A.V. Formirovanie tekhnogennykh prirodnoterritorialnykh kompleksov neftegazovykh mestorozhdeniy severa Sibiri [Formation of technogenic natural-territorial complexes of oil and gas fields in the North of Siberia]. Sbornik nauchnykh trudov aspirantov i molodykh uchenykh Sibirskoy gosudarstvennoy geodezicheskoy akademii [Collection of scientific works of postgraduates and young scientists of the Siberian State Geodesic Academy]. Ed. by T.A. Shirokova. Novosibirsk, SGGA Publ., 2004. pp. 19-24.

3. Dubrovskiy A.V. Bazovye printsipy geoinformatsionnogo obespecheniya bezopasnoy ekspluatatsii promyshlennykh ob'ektov 
[Basic principles of geoinformation support for safe operation of industrial facilities]. Vserossiyskaya nauchnaya Internetkonferentsiya s mezhdunarodnym uchastiem: materialy konferentsii [All-Russian Scientific Internet conference with international participation: materials of the conference]. Kazan, June 5, 2014. Kazan, IP Sinyaev D.N. Publ., 2014. pp. 14-17.

4. Karpik A.P. Kontseptsiya geoinformatsionnogo prostranstva [The concept of geoinformation space]. Materialy mezhdunarodnoy nauchno-tekhnicheskoy konferentsii, posvyashchennoy 225-letiyu $M I I G A i K$ [Materials of the international scientific and technical conference dedicated to the $225^{\text {th }}$ anniversary of MIIGAiK]. Moscow, MIIGAiK Publ., 2004. pp. 434-438.

5. Dolgopolov D.V. The use of remote sensing data in the formation of the geoinformation space of pipeline transport. Vestnik Sibirskogo gosudarstvennogo universiteta geosistem i tekhnologiy (SGUGiT), 2020, vol. 25, no. 3, pp. 151-159. In Rus. DOI: 10.33764/2411-1759-2020-25-3-151-159

6. «Stroytransgaz» obustroit infrastrukturu Chayandinskogo neftegazokondensatnogo mestorozhdeniya [«Stroytransgaz» will equip the infrastructure of the Chayandinsky oil and gas condensate field]. Business News Agency LLC Website. Available at: https:// abnews.ru/tag/zao-strojtransgaz/ (accessed 07 February 2021).

7. Savinykh V.P., Krapivin V.F., Potapov I.I. Informatsionnye tekhnologii $v$ sistemakh ekologicheskogo monitoring [Information technologies in environmental monitoring systems]. Moscow, OOO «Geodezkartizdat» Publ., 2007. 392 p.

8. Savinykh V.P., Tsvetkov V.Ya. Geodata as system information resource. Herald of the Russian Academy of Sciences, 2014, vol. 84, no. 9, pp. 826-829. In Rus.

9. Zverev A.T., Malinnikov V.A. Space geoecological monitoring for Russian North. Proceedings of the Higher Educational Institutions. Izvestia vuzov «Geodesy and aerophotosurveying», 2011, no. 6, pp. 68-73. In Rus.

10. Bondur V.G. Aerokosmicheskiy monitoring neftegazonosnykh territoriy i ob'ektov neftegazovogo kompleksa. Realnosti i perspektivy [Aerospace monitoring of oil and gas-bearing territories and objects of the oil and gas complex. Realities and prospects]. Aerokosmicheskiy monitoring ob'ektov neftegazovogo kompleksa [Aerospace monitoring of oil and gas complex objects]. Ed. by academician V.G. Bondur. Moscow, Nauchnyy mir Publ., 2012. pp. $15-37$.

11. Karpik A.P. Metodologicheskie $i$ tekhnologicheskie osnovy geoinformatsionnogo obespecheniya territoriy: monografiya [Methodological and technological bases of geoinformation support of territories: monograph]. Novosibirsk, SGGA Publ., 2004. $260 \mathrm{p}$.

12. Markelov D.A., Markelov A.V., Mineeva N.Ya., Grigoreva M.A., Akolzin A.P., Shapovalov D.A., Khutorova A.O. Methodology of geoecological standardization of the territory as the basis of geoecological safety. Problems of regional ecology, 2017, no. 3, pp. 16-25. In Rus.

13. Lisitskiy D. V. Osnovnye printsipy tsifrovogo kartografirovaniya mestnosti [Basic principles of digital mapping of the area]. Moscow, Nedra Publ., 1988. 264 p.

14. Ustavich G. A., Utrobina E. S. A new type of cartographic works on the regions of the subjects of the Russian Federation for a wide range of consumers] Proceedings of the Higher Educational Institutions. Izvestia vuzov "Geodesy and aerophotosurveying》, 2012, no. 2-1, pp. 76-80. In Rus.

15. Plotnikova A.S., Yershov D.V., Kharitonova A.O., Shulyak P.P., Bartalev S.A., Stytsenko F.V. Spatial assessment of modern forest fire regimes in Russia. Current problems in remote sensing of the Earth from space, 2019, vol. 16, no. 5, pp. 228-240. In Rus.

16. Melkiy V.A. Theoretical foundations and principles of building a unified system for monitoring the natural environment and the technosphere. Proceedings of the Higher Educational Institutions. Izvestia vuzov «Geodesy and aerophotosurveying», 2002, no. 2, pp. 89-97. In Rus.

17. RD-13.020.40-KTN-025-14. Magistralny truboprovodny transport nefti $i$ nefteproduktov. Trebovaniya $k$ razrabotke plana po preduprezhdeniyu i likvidatsii razlivov nefti (nefteproduktov) na perekhodakh MN (MNPP) cherez vodnye pregrady, PAO «Transneft» [PD-13.020.40-KTH-025-14. Trunk pipeline transportation of oil and oil products. Requirements for the development of a plan for the prevention and liquidation of oil (petroleum) spills on MN (MNPP) transitions through water barriers]. Moscow, PJSC «Transneft», 2014. $15 \mathrm{p}$.

18. Markelov D.A., Markelov A.V., Mineeva N.Ya., Akolzin A.P., Kochurov B.I., $\quad$ Shapovalov D.A., $\quad$ Khutorova A.O., Grigoreva M.A., Chukmasova E.A. Oil pollution of Chechen landscapes: recognition on the ground - «Technologies at a glance». Ecology of Urbanized Territories, 2018, no. 2, pp. 52-60. In Rus.

19. Castillo F. Managing Information Technology. Luxembourg, Springer, 2016. $246 \mathrm{p}$.

20. Arun S.B., Kesavan K., Parivallal S. Recent advances in health monitoring and assessment of inservice oil and gas buried pipelines. Journal of the Institution of Engineers (India): Series A, 2018, vol. 99, pp. 729-740. DOI: 10.1007/s40030-018-0316-5

21. Mezhova L.A., Lugovskoy A.M., Gladkiy Yu.N., Glazyeva A.B., Sushkova O.Yu., Vampilova L.B., Sokolova A.A., Lugovskaya L.A. Geo-ecological Analysis of the effects of pipe-line transport on the environment of transit regions (Voronezh Region, Russia). South of Russia: ecology, development, 2019, vol. 14, no. 4, pp. 98-110. In Rus. DOI: 10.18470/1992-1098- 2019-4-98-110.

22. Jayakrishnan R., Srinivasan R., Santhi C., Arnold J.G. Advances in the application of the SWAT model for water resources management. Hydrological Processes, 2005, vol. 19, no. 3, pp. 749-762.

23. Frasson R.P.d.M., Pavelsky T.M., Fonstad M.A., Durand M.T., Allen G.H., Schumann G., Lion C., Beighley R.E., Yang X. Global relationships between river width, slope, catchment area, meander wavelength, sinuosity, and discharge. Geophysical Research Letters, 2019, vol. 46, no. 6, pp. 3252-3262.

24. Romanovskiy R.V. Application of computer modeling methods of flood zones at maximum design water levels for solving project tasks in the disturbed lands recultivation and design of buildings and facilities near water bodies. Bulletin of the Tomsk Polytechnic University. Geo Assets Engineering, 2019, vol. 330, no. 2, pp. 186-201. In Rus.

25. Dingman L. Physical hydrology. Long Grove, Illinois, Waveland press, Inc., 2015. 643 p.

26. Yongzhi L., Wenting Z., Xinmin C. Flood emergency management using hydrodynamic modelling. Procedia Engineering, 2012, vol. 28, pp. 750-753. DOI: https://doi.org/10.1016/ i.proeng.2012.01.802

27. Pay-per-hour water modelling. MIKE Powered by DHI. Available at: https://www.mikepoweredbydhi.com/products/mike-on-saas (accessed 7 February 2021).

28. CESDb.com Civil Engineering Software Database. Available at: https://www.cesdb.com/hydraulic-engineering/ (accessed 7 February 2021).

29. Pyankov S.V. Shikhov A.N. Geoinformatsionnoe obespechenie modelirovaniya gidrologicheskikh protsessov $i$ yavleniy: monografiya [Geoinformational support of modeling of hydrological processes and phenomena: monograph]. Perm, Perm State University Publ., 2017. 148 p.

30. Novakovsky B.A., Permyakov R.V. Kompleksnoe geoinformatsionno-fotogrammetricheskoe modelirovanie relefa [Complex geoinformation-photogrammetric modeling of relief]. Moscow, MIIGAiK Publ., 2019. 175 p.

31. Pike R.J., Evans I.S., Hengl T. Ch. 1. Geomorphometry: a breif guide. Geomorphometry: Concepts, Software, Applications. Developments in Soil Science. Eds. T. Hengl, H.I. Reuter. Elsevier, 2008, vol. 33, pp. 3-30. DOI: http://dx.doi.org/10.1016/S01662481(08)00001-9

32. Li Z.L., Zhu Q., Gold C. Digital terrain modeling. Principles and methodology. CRC Press, 2005. 318 p. DOI: https://doi.org/ $10.1201 / 9780203357132$

33. Hu Z., Peng J., Hou Y., Shan J. Evaluation of recently released open global digital elevation models of Hubei, China. Remote Sensing, 2017, vol. 9, no. 3, 262 p. DOI: https://doi.org/10.3390/ rs9030262

34. Manfreda S., Nardi F., Samela C., Grimaldi S., Taramasso A.C., Roth G., Sole A. Investigation on the use of geomorphic approaches for the delineation of flood prone areas. Journal Hydrology, 2014, vol. 517, pp. 863-876 DOI: https://doi.org/ 10.1016/j.jhydrol.2014.06.009

35. Avrunev E.I., Ustavich G.A., Grekov, A.O., Nikonov A.V., Melkiy V.A., Dolgopolov D.V. Features of deformation monitoring of engineering structures in permafrost conditions. 
Bulletin of the Tomsk polytechnic university. Geo assets engineering, 2020, vol. 331, no. 7, pp. 188-201. In Rus. DOI: https://doi.org/ 10.18799/24131830/2020/7/2729

36. Hausamann D., Zirnig W., Schreier G., Strobl P. Monitoring of gas pipelines - a civil UAV application. Aircraft Engineering and Aerospace Technology, 2005, vol. 77, no. 5, pp 352-360. DOI: https://doi.org/10.1108/00022660510617077

37. Kovačič B., Kamnik R. Accuracy of trigonometric heighting and monitoring the vertical displacements. Engineering modeling, 2007, no. 20, 1-4, pp. 77-84. Available at: https://www. researchgate.net/publication/293730162_Accuracy_of_trigonomet ric_heighting_and_monitoring_the_vertical_displacements (accessed 7 February 2021).

38. Khlebnikova T.A., Opritova O.A., Aubakirova S.M. Experementalnye issledovaniya tochnosti postroeniya fotogrammetricheskoy modeli po materialam BPLA [Experimental studies of photogrammetric model accuracy by UAV]. Sbornik materialov Mezhdunarodnoy nauchnoy konferentsii. Interekspo Geo-Sibir'-2018 [Proceedings of Interexpo GEO-Siberia-2018. International Scientific Conference]. Novosibirsk, SSGA Publ., 2018. Vol. 1, pp. 32-37.

39. Hawker L., Rougier J., Neal J., Bates P., Archer L., Yamazaki D. Implications of Simulating Global Digital Elevation Models for Flood Inundation Studies. Water Resources Research, 2018, vol. 54, Iss. 10, pp. 7910-7928. DOI: https://doi.org/10.1029/2018WR023279

40. Niyazi B., Zaidi S.M.F., Masoud M.H.Z. Comparative study of different types of digital elevation models on the basis of drainage morphometric parameters (case study of Wadi Fatimah Basin, KSA). Earth Systems and Environment, Springer, 2019, vol. 3 , no. 3, pp. 539-550. DOI: https://doi.org/10.1007/s41748-01900111-2

41. Yue L., Shen H., Zhang L., Zheng X., Zhang F., Yuan Q. Highquality seamless DEM generation blending SRTM-1, ASTER GDEM v2 and ICESat/GLAS observations. Journal of Photogrammetry and Remote Sensing (ISPRS), 2017, vol. 123, pp. 20-34. DOI: https://doi.org/10.1016/j.isprsjprs.2016.11.002

42. Santillan J.R., Makinano-Santillan M., Makinano R.M. Vertical accuracy assessment of ALOS World 3D - $30 \mathrm{~m}$ Digital Elevation Model over northeastern Mindanao, Philippines. 2016 IEEE International Geoscience and Remote Sensing Symposium (IGARSS). 2016. pp. 5374-5377. Available at: https:/ieeexplore.ieee.org/ document/7730400 (accessed 7 February 2021).

43. Bannari A., Kadhem G., El-Battay A., Hameid N. Comparison of SRTM-V4.1 and ASTER-V2.1 for Accurate topographic attributes and hydrologic indices extraction in flooded areas. Journal of Earth Science and Engineering, 2018, vol. 8, no. 1, pp. 8-30. Available at: https://pdfs.semanticscholar.org/958e/e8773691 ac91f61914277400872db025e7a1.pdf (accessed 7 February 2021).

44. Chen C., Yang S., Li Y. Accuracy assessment and correction of SRTM DEM using ICESat/GLAS data under data coregistration. Remote Sensing, 2020, vol. 12, no. 20, pp. 3435 . DOI: https://doi.org/10.3390/rs12203435

45. Skrypitsyna T.N., Florinskiy I.V., Lushchikova O.S. Comparative evaluation of the accuracy of quasi-global terrain models AW3D30 DSM, ASTER GDEM and SRTM1 DEM. Proceedings of the Higher Educational Institutions. Izvestia vuzov «Geodesy and aerophotosurveying», 2017, no. 5, pp. 86-90. In Rus.

46. Caglar B., Belek K., Mekik C., Ozendi M. On the vertical accuracy of the ALOS world 3D-30m digital elevation model. Remote Sensing Letters, 2018, vol. 9, no. 6, pp.607-615. DOI https://doi.org/10.1080/2150704X.2018.1453174

47. Imai T., Katayama H., Imai H., Hatooka Y., Suzuki Sh., Osawa Y. Current status of Advanced Land Observing Satellite-3 (ALOS-3).
Proceedings of SPIE 7826, Sensors, Systems, and Next-Generation Satellites XIV. France, Toulouse, Sept. 20-23, 2010. Paper 78260C. DOI: https://doi.org/10.1117/12.866289

48. Tarolli P., Mudd S.M. Introduction to remote sensing of geomorphology. Developments in Earth Surface Processes, 2020, vol. 23, pp. XIII-XV. DOI: https://doi.org/10.1016/B978-0-44464177-9.09992-6

49. Avrunev E.I., Chernov A.V., Dubrovsky A.V., Komissarov A.V., Pasechnik E.Yu. Technological aspects of constructing 3D-model of engineering structures in the cities of the RF Arctic Region. Bulletin of the Tomsk Polytechnic University. Geo Assets Engineering, 2018, vol. 329, no. 7, pp. 131-137. In Rus. Available at: http://izvestiya.tpu.ru/archive/article/view/2066 (accessed 7 February 2021)

50. Ustavich G.A., Avrunev E.I., Salnikov V.G., Popov V.K. Features of deformation monitoring of engineering structures in permafrost conditions. Bulletin of the Tomsk polytechnic university. Geo assets engineering, 2018, vol. 329, no. 4, pp. 97-109. In Rus. Available at: http://izvestiya.tpu.ru/archive/article/view/2018 (accessed 7 February 2021).

51. Sevastiyanov N.N. Proposals for development of PJSC Gazprom's corporate geoinformation system based on use of aerospace information. Gas Industry of Russia, 2018, no. 7 (771), pp. 18-25. In Rus.

52. Melkiy V.A., Verkhoturov A.A., Dolgopolov D.V., Burykin A.N., Ilin V.V., Galtsev A.A., Zaripov O.M., Novikov D.G., Belyanina Ya.P., Eremenko I.V. Environmental monitoring and measures to reduce the possible negative impact of pipelines (Sakhalin 2 Project) on the environment of Sakhalin Island. Proceedings of the Higher Educational Institutions. Izvestia vuzov «Geodesy and aerophotosurveying», 2015, no. 4, pp. 101-108. In Rus.

53. Liu W.T., Kogan F.N. Monitoring regional drought using the vegetation condition index. International Journal of Remote Sensing, 1996, vol. 17, no. 14, pp. 2761-2782. DOI: https://doi.org/ 10.1080/01431169608949106

54. Postanovlenie Pravitelstva RF ot 31 dekabrya 2020 g. № 2451 «Ob utverzhdenii Pravil organizatsii meropriyatiy po preduprezhdeniyu i likvidatsii razlivov nefti i nefteproduktov na territorii Rossiyskoy Federatsii, za isklyucheniem vnutrennikh morskikh vod Rossiyskoy Federatsii i territorialnogo morya Rossiyskoy Federatsii, a takzhe o priznanii utrativshimi silu nekotorykh aktov Pravitelstva Rossiyskoy Federatsii» [The resolution of the RF Government dated 31 December 2020, No. 2451 «On approval of Rules of organization of measures for prevention and elimination of oil spills and oil products on the territory of the Russian Federation, except for the internal waters of the Russian Federation and the territorial sea of the Russian Federation and the annulment of certain acts of the Government of the Russian Federation»]. Information and legal portal «Garant.RU». Available at: http://www.garant.ru/products/ipo/prime/doc/ 400070332/ (accessed 7 February 2021).

55. Pravila okhrany magistralnykh truboprovodov. Normativnye dokumenty po bezopasnosti, nadzornoy i razreshitelnoy deyatelnosti v neftyanoy i gazovoy promyshlennosti [Rules for protection of trunk pipelines. Regulatory documents on safety, supervision and licensing activities in the oil and gas industry]. Eds. Yu.A. Dadonov, S.N. Mokrousov. Moscow, Scientifictechnical center for industrial safety of Gosgortekhnadzor of Russia Publ., 2004. Iss. 14, 8 p.

Received: 8 February 2021.

\section{Information about the authors}

Daniil V. Dolgopolov, Cand. Sc., leading researcher, SpacInfo Geomatics JSC.

Vyacheslav A. Melkiy, Dr. Sc., leading researcher, laboratory of Volcanology and volcano hazard of the Institute of Marine Geology and Geophysics of the Far Easten Branch of Russian Academy of Science.

Alexey A. Verkhoturov, Cand. Sc., senior researcher, Center for collective use of the Institute of Marine Geology and Geophysics of the Far Easten Branch of Russian Academy of Science. 